\title{
Measurements of the electron swarm parameters of R1225ye (Z) (C3HF5) and its mixtures with N2 and $\mathrm{CO} 2$
}

\section{Journal Article}

Author(s):

Pachin, Juriy (D); Hösl, Andreas (D); Franck, Christian (1)

Publication date:

2019-04-03

Permanent link:

https://doi.org/10.3929/ethz-b-000303118

Rights / license:

In Copyright - Non-Commercial Use Permitted

Originally published in:

Journal of Physics D 52(23), https://doi.org/10.1088/1361-6463/ab0f5c 
This is an author-created, un-copyedited version of an article submitted to J. Phys. D: Appl. Phys. IOP Publishing Ltd is not responsible for any errors or omissions in this version of the manuscript or any version derived from it. Once it is published, it will be available at http://iopscience.iop.org/journal/0022-3727

\title{
Measurements of the Electron Swarm Parameters of R1225ye(Z) $\left(\mathrm{C}_{3} \mathrm{HF}_{5}\right)$ and its Mixtures with $\mathrm{N}_{2}$ and $\mathrm{CO}_{2}$
}

\author{
Juriy Pachin and Christian M. Franck \\ ETH Zurich, High Voltage Laboratory, Physikstr. 3, 8092 Zurich, Switzerland \\ E-mail: jpachin@ethz.ch
}

\begin{abstract}
The electron swarm parameters of R1225ye(Z) (cis-1,2,3,3,3-pentafluoroprop-1-ene) and its mixtures with the buffer gases $\mathrm{N}_{2}$ and $\mathrm{CO}_{2}$ from $1 \%$ to $50 \%$ are experimentally investigated using a pulsed Townsend experiment. The analysis of the electron avalanche displacement current yields the effective ionization rate coefficient, the electron drift velocity and the longitudinal electron diffusion coefficient. To assess the potential of the gas as an insulating medium for medium or high voltage applications, the density-reduced critical electric field $(E / N)_{\text {crit }}$ is obtained. In pure R1225ye $(\mathrm{Z}),(E / N)_{\text {crit }}$ increases with increasing pressure from around $280 \mathrm{Td}$ at $2 \mathrm{kPa}$ to $300 \mathrm{Td}$ at $14 \mathrm{kPa}$. Mixtures of R1225ye(Z) with $\mathrm{N}_{2}$ and $\mathrm{CO}_{2}$ show almost no synergy. Finally a comparison to $\mathrm{HFO} 1234 \mathrm{ze}(\mathrm{E})$ and $\mathrm{l}_{-} \mathrm{C}_{3} \mathrm{~F}_{6}$ is given.
\end{abstract}

\section{Introduction}

The computational screening method of Rabie et al. $[1,2]$ for new high-voltage insulation gases with low global warming potential (GWP), showed R1225ye(Z) as one of the promising candidates. R1225ye(Z) is commercially available and has a molecular structure similar to the previously investigated $\operatorname{HFO} 1234 \mathrm{ze}(\mathrm{E})[3,4]$ and $\mathrm{l}_{-} \mathrm{C}_{3} \mathrm{~F}_{6}[5]$. Due to these reasons, pure R1225ye(Z) and its mixtures with buffer gases $\mathrm{N}_{2}$ and $\mathrm{CO}_{2}$ were chosen to be investigated in a pulsed Townsend experiment, to obtain their electron swarm parameters and determine $(E / N)_{\text {crit }}$. This allows, in combination with the knowledge of the liquefaction temperature, the first estimation of the insulation performance.

In high-voltage equipment, $\mathrm{SF}_{6}$ is predominately used as a gaseous insulation medium. The main advantages are its high $(E / N)_{\text {crit }}$, chemical stability, zero toxicity, and in particular, a low liquefaction temperature. However, the main disadvantage of $\mathrm{SF}_{6}$ is its GWP - being 23500 times that of $\mathrm{CO}_{2}$ on a 100-year time horizon [6] - which therefore requires a replacement by an environment-friendly substance.

This work is structured as follows: Section 2 describes the properties of R1225ye(Z), the pulsed Townsend setup, and the method for analyzing measurements. Section 3 presents the obtained electron swarm parameters of pure $\mathrm{R} 1225 \mathrm{ye}(\mathrm{Z})$ and its mixtures with $\mathrm{N}_{2}$ and $\mathrm{CO}_{2}$ - for different mixing ratios and pressures. The swarm parameters are: the effective ionization rate coefficient $k_{\text {eff }}$, electron drift velocity $w_{\mathrm{e}}$, and electron longitudinal diffusion coefficient $N D_{\mathrm{L}}$. In Section 4, the three-body electron attachment properties of R1225ye $(\mathrm{Z})$ are discussed, the $(E / N)_{\text {crit }}$ of different mixtures with $\mathrm{N}_{2}$ and $\mathrm{CO}_{2}$ are summarized, and a comparison with $\mathrm{HFO} 1234 \mathrm{ze}(\mathrm{E})$ and $\mathrm{l}_{3} \mathrm{C}_{3} \mathrm{~F}_{6}$ is shown.

\section{Methods}

\subsection{R1225ye(Z)}

R1225ye(Z) is also known as HFO1225ye(Z), (Z)HFC-1225ye, cis-1,2,3,3,3-pentafluoroprop-1-ene, (Z)1,2,3,3,3-Pentafluoropropene, $\mathrm{CF} 3 \mathrm{CF}=\mathrm{CHF}(\mathrm{Z})$ or $\mathrm{C}_{3} \mathrm{HF}_{5}$ with the CAS number 5528-43-8. The molecular structure of R1225ye(Z) is illustrated in figure 5(a). It was considered as a medical propellant [7], or by the automotive industry as a possible component of an alternative refrigerant blend with low GWP [8]. R1225ye $(\mathrm{Z})$ has a GWP $<1$ with an atmospheric lifetime of 8.5 days [6]. The acute toxicity $\mathrm{LC}_{50}$ for $4 \mathrm{~h}$ inhalation by rats is above $50000 \mathrm{ppm}$. Rat inhalation studies for 28 days show toxicological effects at 10000 , 25 000, and 50000 ppm concentrations [7]. R1225ye(Z) is claimed to be non-flammable and chemically stable [8-10]. The molecular mass is $132.03 \mathrm{~g} / \mathrm{mol}$. The normal boiling point is $253.6 \mathrm{~K}$, the vapor pressure at $293.15 \mathrm{~K}$ is $0.436 \mathrm{MPa}$, the ideal gas specific heat at constant pressure and $300 \mathrm{~K}$ is $101.9 \mathrm{~kJ} \cdot(\mathrm{kmol} \cdot \mathrm{K})^{-1}$ [8]. The normal boiling point of $\mathrm{R} 1225 \mathrm{ye}(\mathrm{Z})$ is around $44 \mathrm{~K}$ above the boiling point of $\mathrm{SF}_{6}$. To avoid liquefaction by similar operating conditions to $\mathrm{SF}_{6}$ equipment, R1225ye(Z) has to be used in mixture with buffer gases. The $(E / N)_{\text {crit }}$ of these gas mixtures must be also investigated, as it can exceed the linear combination of $(E / N)_{\text {crit }}$ of the individual gas components weighted by their mole fraction. This beneficial effect for the insulation application is called synergy [11, 12]. The maximal mole-fractions of R1225ye $(\mathrm{Z})$ in $\mathrm{N}_{2}$ and $\mathrm{CO}_{2}$, for technically relevant pressures and temperatures are listed in table 1.

The purity of the R1225ye(Z) sample was $97 \%$, the impurity consisting mainly of the R1225ye(E)-isomer [13] . The purity of $\mathrm{N}_{2}$ was 6.0 , and the purity of $\mathrm{CO}_{2}$ 
Table 1. Maximal mole-fraction of R1225ye(Z) in mixture with $\mathrm{N}_{2}$ and $\mathrm{CO}_{2}$, assuming ideal gases, filling at $293 \mathrm{~K}$, considering different minimal operating temperatures according to the requirements of IEC 62271-1 [14].

\begin{tabular}{|c|c|c|c|}
\hline \multirow{2}{*}{$\begin{array}{c}\text { minimal } \\
\text { operating } \\
\text { temperature (K) }\end{array}$} & filling & \multicolumn{3}{|c|}{ maximal mole frac- } \\
pressure & at $293 \mathrm{~K}$ & \multicolumn{2}{|c|}{ tion of $\mathrm{R} 1225 \mathrm{ye}(\mathrm{Z})(\%)$} \\
in $\mathrm{N}_{2}$ & in $\mathrm{CO}_{2}$ \\
\hline (in- and outdoor) 248 & 140 & 67 & 65 \\
& 600 & 16 & 11 \\
\hline (indoor) 258 & 140 & 99 & 99 \\
& 600 & 23 & 18 \\
\hline (outdoor) 263 & 140 & 100 & 100 \\
& 600 & 23 & 19 \\
\hline (indoor) 268 & 140 & 100 & 100 \\
& 600 & 33 & 29 \\
\hline
\end{tabular}

was 4.8. The gases were mixed by partial pressures under the assumption of validity of the ideal gas law.

\subsection{Experimental Setup}

The measurements of electron swarm parameters were performed in the pulsed Townsend (PT) setup, described in detail by Dahl et al. [15]. A schematic of the PT-experiment is shown in Figure 1. For the investigation, the gas was filled into a pressure vessel containing two electrodes with a Rogowski profile and an adjustable gap distance $d$. Before filling the gases, the vessel was evacuated to a pressure below $1 \mathrm{~Pa}$. A negative voltage $U$ in the range from $-0.2 \mathrm{kV}$ up to $-40 \mathrm{kV}$ has been applied to the back-illuminated photocathode, while the anode was grounded. A short UV-laser pulse, with a wavelength of $266 \mathrm{~nm}$, a duration of $1.5 \mathrm{~ns}$ FWHM and a repetition rate of $20 \mathrm{~Hz}$, releases approximately $10^{7}$ electrons from the cathode. Due to the applied homogeneous electric field $E$, the released electrons drift in a swarm towards the anode and collide with sample gas molecules in the vessel. The collisions may lead to ionization and attachment events. The ionization forms positive ions and simultaneously releases new free electrons. The attachment forms negative ions by capturing free electrons. Consequently, the number of electrons in the swarm increases or decreases.

All measurements were performed at a monitored room temperature. Each $E / N$ value was measured at several pressure levels and at four discrete electrode distances, namely $19 \mathrm{~mm}, 17 \mathrm{~mm}, 15 \mathrm{~mm}$, and $13 \mathrm{~mm}$ for each pressure level.

\subsection{Measurement Analysis}

The displacement current resulting from the electron and ion drift in the gap was measured at the anode, thus allowing extraction of the electron swarm parameters with the method described by Chachereau et al. [3]. Examples of electron current waveforms are

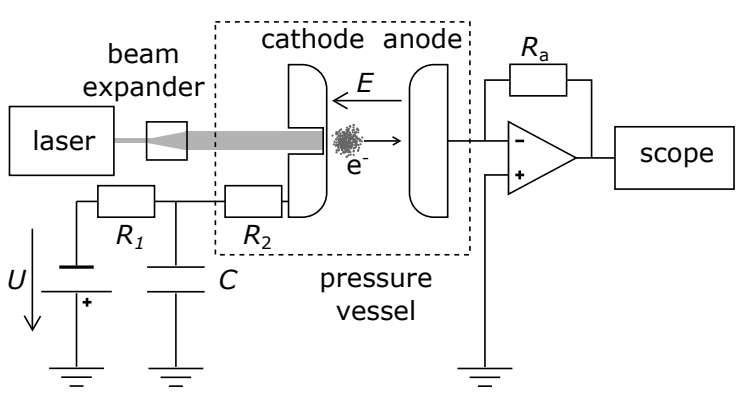

Figure 1. Schematic of the pulsed Townsend experiment $\left(R_{1}=180 \Omega, R_{2}=100 \Omega, C=2 \mathrm{nF}\right)[4]$

shown in figure 2. The electron swarm is modeled with a Gaussian spatial distribution along the propagation axis. The corresponding electron current $I_{\mathrm{e}}$ can be expressed for $t \geqslant 0$ as equation (1) [3, 15]

$I_{\mathrm{e}}(t)=\frac{I_{0}}{2} \exp \left(k_{\mathrm{eff}} N t\right)\left(1-\operatorname{erf}\left(\frac{t-t_{\mathrm{e}}}{\sqrt{2 \tau_{\mathrm{D}}} t}\right)\right)$,

where $I_{0}$ is the electron current at time $t=0, k_{\text {eff }}$ the effective ionization rate coefficient, $t_{\mathrm{e}}$ the electron drift time in the gap, and $\tau_{\mathrm{D}}$ the characteristic time for longitudinal electron diffusion. The canonical error function 'erf' describes the electron swarm absorption at the anode. It is assumed that the laser pulse releases the electrons in an initial distribution of a Dirac delta function. By fitting equation (1), the swarm parameters: effective ionization rate coefficient $k_{\text {eff }}$, bulk electron drift velocity $w_{\mathrm{e}}=d / t_{e}$, and electron longitudinal diffusion coefficient $N D_{\mathrm{L}}=w_{\mathrm{e}}^{2} \tau_{\mathrm{D}} N / 2$ are obtained. They depend on the density-reduced electric field $E / N$ with the unit Townsend $\left(1 \mathrm{Td}=10^{-21} \mathrm{Vm}^{2}\right)$. The gas number density $N=p /\left(k_{\mathrm{B}} \cdot T\right)$ depends on the gas pressure $p$ and the temperature $T, k_{B}$ is the Boltzmann constant.

The main quantity to characterize the dielectric performance of an insulating gas in a PT-experiment is the density-reduced critical electric field $(E / N)_{\text {crit }}$. It corresponds to the breakdown field in a homogeneous field configuration for large electrode gaps and high pressures. The condition of $E / N=(E / N)_{\text {crit }}$ is fulfilled if the number of electrons in the swarm stays constant, i.e. $k_{\text {eff }}=0$. If electron attachment is dominant, the number of electrons in the swarm decreases, consequently $k_{\text {eff }}<0$ and $E / N<(E / N)_{\text {crit }}$. If ionization is dominant, the number of electrons in the swarm increases, i.e. $k_{\text {eff }}>0$ and $E / N>(E / N)_{\text {crit }}$. These relations are illustrated by the example current traces in figure 2. 


\section{Results}

The swarm parameters were obtained for the widest possible $E / N$ range. Outside this range the signal is too low for the evaluation. This was the case for strong electron attachment and high pressures. For strong electron attachment and a sufficiently strong signal, the current decreased to zero before the swarm could reach the anode. Consequently, it was not possible to determine $w_{\mathrm{e}}$ and $N D_{\mathrm{L}}$. For higher pressures the bandwidth of the amplifier was not high enough to obtain $N D_{\mathrm{L}}$. In this work, the most relevant data are presented. The whole set of measurement data is available on the LXcat website, database ETHZ [16, $17]$.

\subsection{R1225ye(Z) at different pressures}

Pure R1225ye(Z) was measured in the pressure range from $2 \mathrm{kPa}$ to $14 \mathrm{kPa}$ - in $2 \mathrm{kPa}$ steps. Sample electron currents are shown in figure 2. In figure $2(\mathrm{a})$, the pressure was kept constant at $2 \mathrm{kPa}$ while the $E / N$ value was changed by changing the cathode voltage. $(E / N)_{\text {crit }}$ is around $280 \mathrm{Td}$. Vice-versa in figure 2(b), the pressure levels were varied, while the $E / N$ value was kept constant at $286 \mathrm{Td}$. With an increasing pressure, $k_{\text {eff }}$ changes from negative to positive values. Figure $3(\mathrm{a})$ shows $k_{\text {eff }}$, as a function of $E / N$ for different pressures in pure R1225ye(Z). $k_{\text {eff }}$ decreases with increasing pressure as already shown in figure 2(b). Consequently, $(E / N)_{\text {crit }}$ increases.

\subsection{R1225ye $(Z) / N_{2}$ mixtures}

Figure 3 shows $k_{\text {eff }}, w_{\mathrm{e}}$, and $N D_{\mathrm{L}}$ as functions of $E / N$ for R1225ye(Z)/ $\mathrm{N}_{2}$ mixtures, with a R1225ye(Z) mole fraction from $5 \%$ to $50 \%$. The pressure was in the range from $2 \mathrm{kPa}$ and - depending on the mixture up to $50 \mathrm{kPa}$. Due to the bandwidth limitation, it was only possible to obtain $w_{\mathrm{e}}$ and $N D_{\mathrm{L}}$ for $2 \mathrm{kPa}$. For the $5 \%, 10 \%$ and $15 \%$ mixtures, $k_{\text {eff }}$ is pressureindependent, whereas in the case of the $50 \%$ mixture, $k_{\text {eff }}$ decreases with increasing pressure. For the $20 \%$ mixture, the pressure dependence of $k_{\text {eff }}$ cannot be observed clearly. $w_{\mathrm{e}}$ in pure $\mathrm{R} 1225 \mathrm{ye}(\mathrm{Z})$ is lower than in pure $\mathrm{N}_{2}$. For R1225ye $(\mathrm{Z}) / \mathrm{N}_{2}$ mixtures, two regions can be distinguished. For $E / N$ values approximately below $120 \mathrm{Td}, w_{\mathrm{e}}$ in mixtures is higher than in pure $\mathrm{N}_{2}$. Above approximately $120 \mathrm{Td}, w_{\mathrm{e}}$ in mixtures is lower than in pure $\mathrm{N}_{2}$, and decreases with increasing R1225ye(Z) fraction. The $N D_{\mathrm{L}}$ values for mixtures are lower than for the pure $\mathrm{N}_{2}$ and decrease with an increasing $\mathrm{R} 1225 \mathrm{ye}(\mathrm{Z})$ fraction.
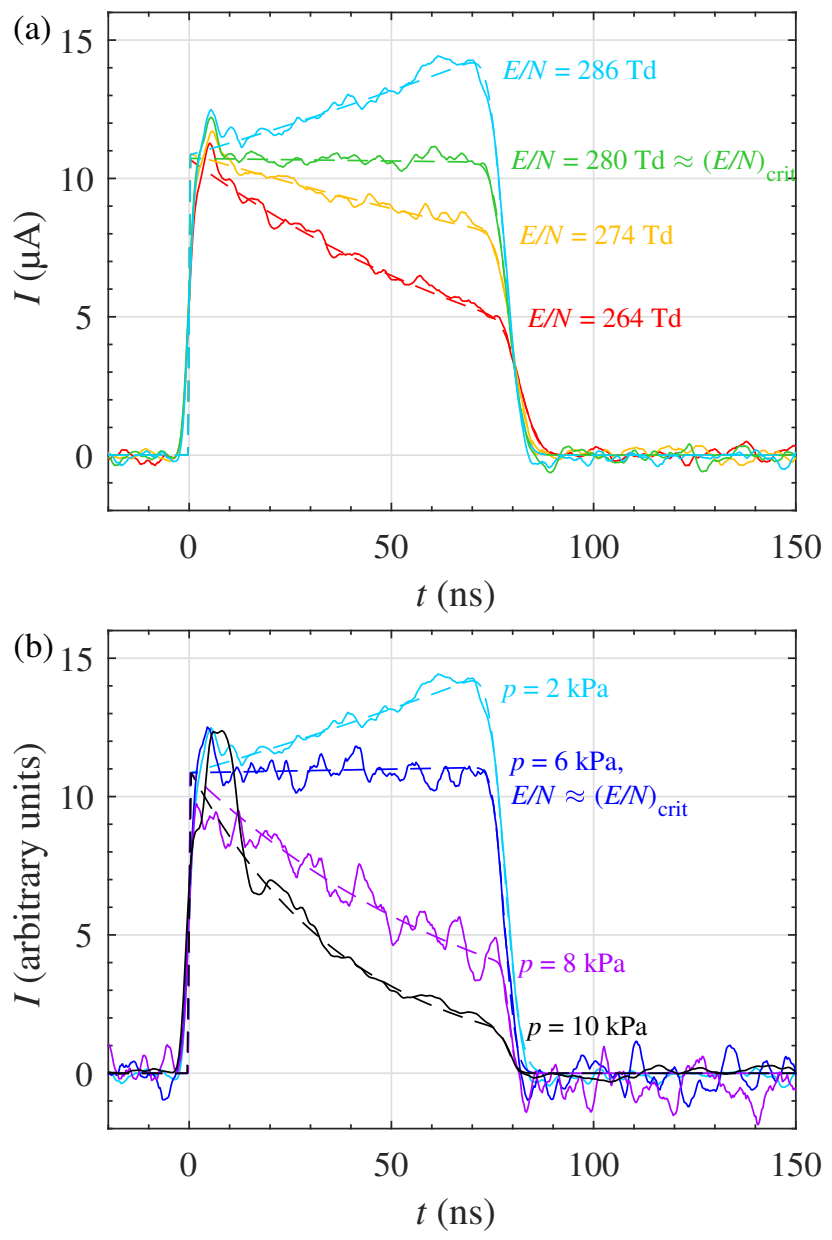

Figure 2. Example electron displacement currents in R1225ye(Z) for an electrode spacing of $13 \mathrm{~mm}$. Solid lines are the extracted electron currents. Dashed lines corresponds to the model of electron current according to equation (1). (a) Fixed pressure of $2 \mathrm{kPa}$ and different $E / N$ values. (b) Fixed $E / N$ value of around $286 \mathrm{Td}$ and different pressure values. The measurements are rescaled to the same initial amplitude for easier comparison.

\subsection{R1225ye $(\mathrm{Z}) / \mathrm{CO}_{2}$ mixtures}

Figure 4 shows $k_{\mathrm{eff}}, w_{\mathrm{e}}$, and $N D_{\mathrm{L}}$ as functions of $E / N$ for $\mathrm{R} 1225 \mathrm{ye}(\mathrm{Z}) / \mathrm{CO}_{2}$ mixtures, with a R1225ye(Z) mole fraction from $5 \%$ to $50 \%$. The pressure was in the range from $2 \mathrm{kPa}$ and - depending on the mixture - up to $10 \mathrm{kPa}$. For all mixtures, $k_{\text {eff }}$ appears to remain pressure-independent for the investigated pressure range. $w_{\mathrm{e}}$ in mixtures from $5 \%$ to $20 \%$ is similar to pure $\mathrm{CO}_{2}$, while in the $50 \%$ mixture, $w_{\mathrm{e}}$ seems to be in between $\mathrm{CO}_{2}$ and pure R1225ye(Z). The $N D_{\mathrm{L}}$ values of mixtures are below the values of pure $\mathrm{CO}_{2}$ and decrease with increasing $\mathrm{R} 1225 \mathrm{ye}(\mathrm{Z})$ percentage. 

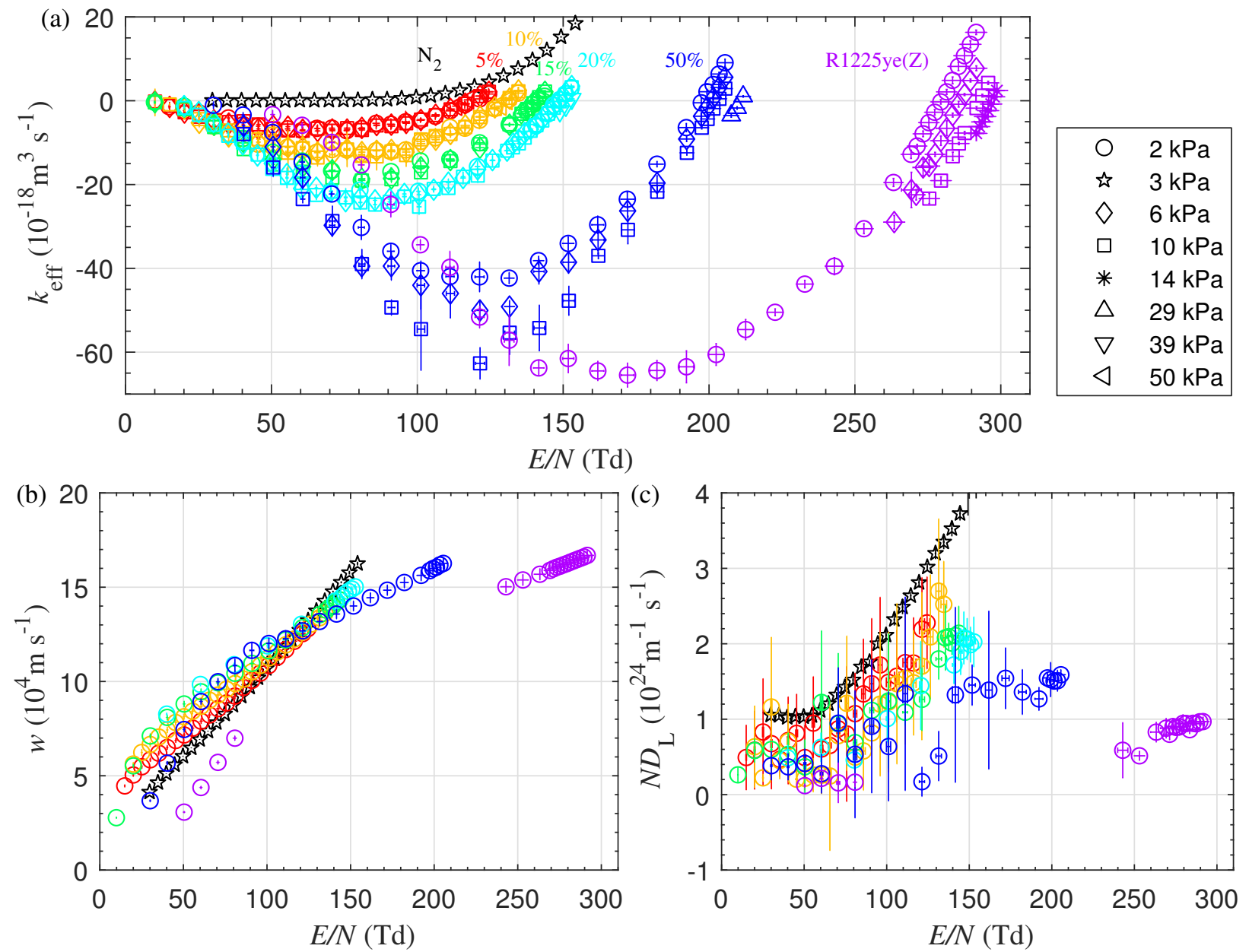

Figure 3. (a) Effective ionization rate coefficient, (b) electron drift velocity, (c) density normalized longitudinal electron diffusion coefficient versus $E / N$ in R1225ye(Z), $\mathrm{N}_{2}$ [18], and their mixtures. The gas mixtures are color-coded. The gas pressures are indicated by different markers. The percentages of $\mathrm{R} 1225 \mathrm{ye}(\mathrm{Z})$ and pressures are indicated in figure (a), the same color and marker code is used for figures (b) and (c).

\section{Discussion}

\subsection{Comparison of R1225ye(Z) with HFO1234ze(E) and $1-C_{3} F_{6}$}

$(E / N)_{\text {crit }}$ of pure R1225ye(Z) increases with increasing gas pressure. This pressure dependence has been observed previously for gases with similar structures, namely $1-\mathrm{C}_{3} \mathrm{~F}_{6} \quad[5]$ and $\operatorname{HFO} 1234 z e(\mathrm{E})$ [3]. As illustrated in figure 5 , these three gases have the same $\mathrm{C}-\mathrm{C}=\mathrm{C}$ backbone structure and the same number of member elements, which are fluorine $(\mathrm{F})$ and hydrogen $(\mathrm{H})$. While $1-\mathrm{C}_{3} \mathrm{~F}_{6}$ has no $\mathrm{H}$-atoms, $\operatorname{HFO} 1234 z e(\mathrm{E})$ has two H-atoms, and R1225ye(Z) with one H-atom is structurally in-between.

The comparison of $(E / N)_{\text {crit }}$ of these three gases is shown in figure 6 . R1225ye $(\mathrm{Z})$ has the highest critical field in the pressure range from $2 \mathrm{kPa}$ to $14 \mathrm{kPa}$. For higher pressures, $(E / N)_{\text {crit }}$ cannot be reliably predicted, as explained in detail in the next subsection.
However, as a rough estimation, upper and lower limits of $(E / N)_{\text {crit }}$ can be given. A linear extrapolation gives the upper limit of $(E / N)_{\text {crit }} \simeq 350 \mathrm{Td}$ at a pressure of $50 \mathrm{kPa}$, and $(E / N)_{\text {crit }} \simeq 415 \mathrm{Td}$ at $94 \mathrm{kPa}$. Here, $94 \mathrm{kPa}$ is the maximum possible pressure of pure R1225ye(Z) that can be achieved without liquefaction down to $248 \mathrm{~K}$ by filling at $293 \mathrm{~K}$. The lower limit is derived under the assumption of an immediate saturation of the pressure dependence and consequently an $(E / N)_{\text {crit }}$ of $300 \mathrm{Td}$. In the case of the upper limit, $(E / N)_{\text {crit }}$ of R1225ye(Z) would be superior to $1-\mathrm{C}_{3} \mathrm{~F}_{6}$ and $\mathrm{HFO} 1234 \mathrm{ze}(\mathrm{E})$. In the case of the lower limit, $(E / N)_{\text {crit }}$ of R1225ye(Z) would be beneath $1-\mathrm{C}_{3} \mathrm{~F}_{6}$, but still superior to $\mathrm{HFO} 1234 \mathrm{ze}(\mathrm{E})$ up to a pressure of at least $45 \mathrm{kPa}$.

As mentioned above, an important aspect of the insulation performance under operating conditions is the boiling point - which limits the possible maximum pressure of the gas. The vapor pressure curve of 

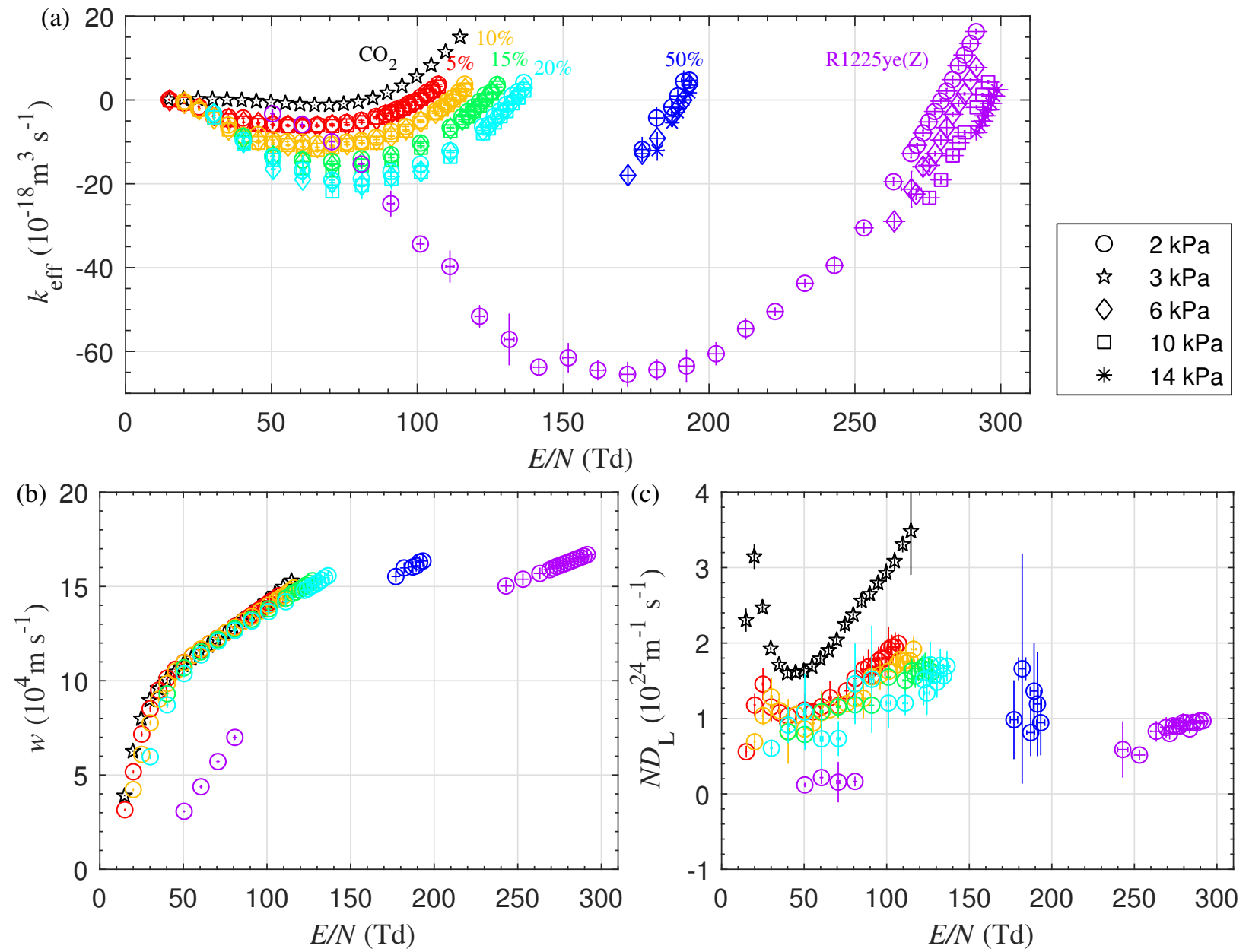

Figure 4. (a) Effective ionization rate coefficient, (b) electron drift velocity, (c) density normalized longitudinal electron diffusion coefficient versus $E / N$ in $\mathrm{R} 1225 \mathrm{ye}(\mathrm{Z}), \mathrm{CO}_{2}$ [18], and their mixtures. The gas mixtures are color-coded. The gas pressures are indicated by different markers. The percentages of R1225ye(Z) and pressures are indicated in figure (a), the same color and marker code is used for figures (b) and (c).<smiles>FC=C(F)C(F)(F)F</smiles>

(a)<smiles>FC(F)=C(F)C(F)(F)F</smiles>

(b)<smiles>FC=CC(F)(F)F</smiles>

(c)
R1225ye(Z), HFO1234ze(E), and $1-\mathrm{C}_{3} \mathrm{~F}_{6}$ are shown in figure 7. The vapor pressure curve of $\mathrm{R} 1225 \mathrm{ye}(\mathrm{Z})$, with a normal boiling point of approximately $253 \mathrm{~K}$, is almost equal to the vapor pressure curve of HFO1234ze(E), irrespective of the different number of H-atoms. Regarding the combination of $(E / N)_{\text {crit }}$ and boiling point, $1-\mathrm{C}_{3} \mathrm{~F}_{6}$ has the best insulation performance of these three gases. However, $1-\mathrm{C}_{3} \mathrm{~F}_{6}$ is supposed to have a high toxicity, with a $\mathrm{LC}_{50}$ for $4 \mathrm{~h}$ inhalation by rats below $3000 \mathrm{ppm}$ [19]. Due to the similar boiling point, the superiority of R1225ye(Z) to HFO1234ze(E) depends on $(E / N)_{\text {crit }}$ and is given up to a pressure of at least $45 \mathrm{kPa}$.

\subsection{Three-body electron attachment to R1225ye(Z)}

igure 5. Molecular structure of (a) R1225ye $(\mathrm{Z}) / \mathrm{C}_{3}$ CAS 5528-43-8, (b) $1-\mathrm{C}_{3} \mathrm{~F}_{6}$, CAS 116-15-4, HFO1234ze(E)/ $\mathrm{C}_{3} \mathrm{H}_{2} \mathrm{~F}_{4}$, CAS 1645-83-6. (c)

The pressure dependence of $(E / N)_{\text {crit }}$ can be explained with the mechanism of three-body electron attachment $[3,22,23]$. This mechanism can be modeled with processes and corresponding rates of dissociative attach- 


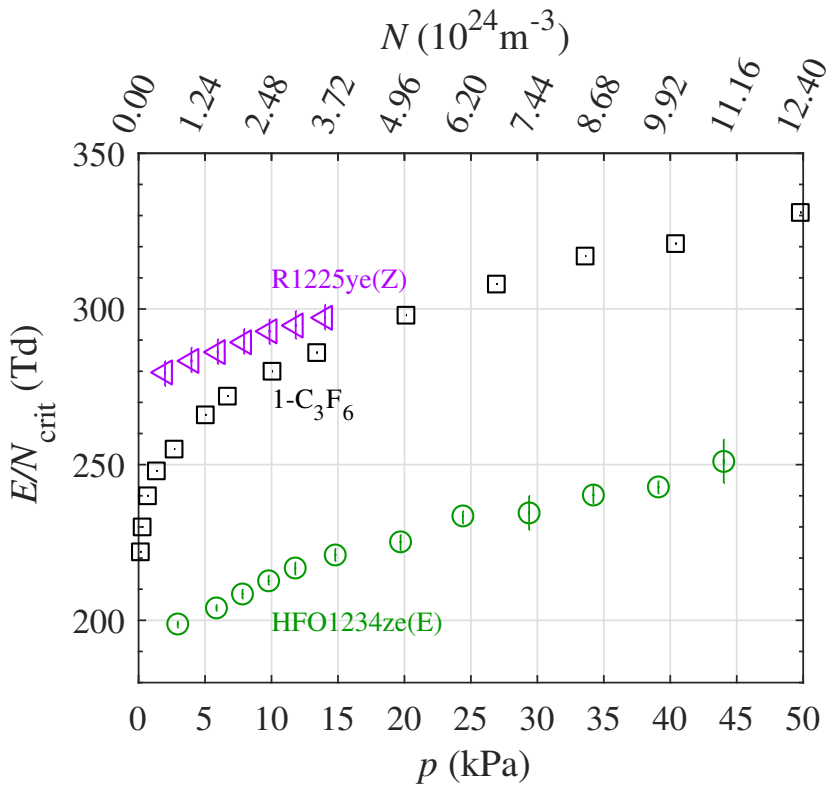

Figure 6. $(E / N)_{\text {crit }}$ of R1225ye(Z), HFO1234ze(E) [3] and $1-\mathrm{C}_{3} \mathrm{~F}_{6}$ [5] as a function of pressure at $293 \mathrm{~K}$ and molecule number density.

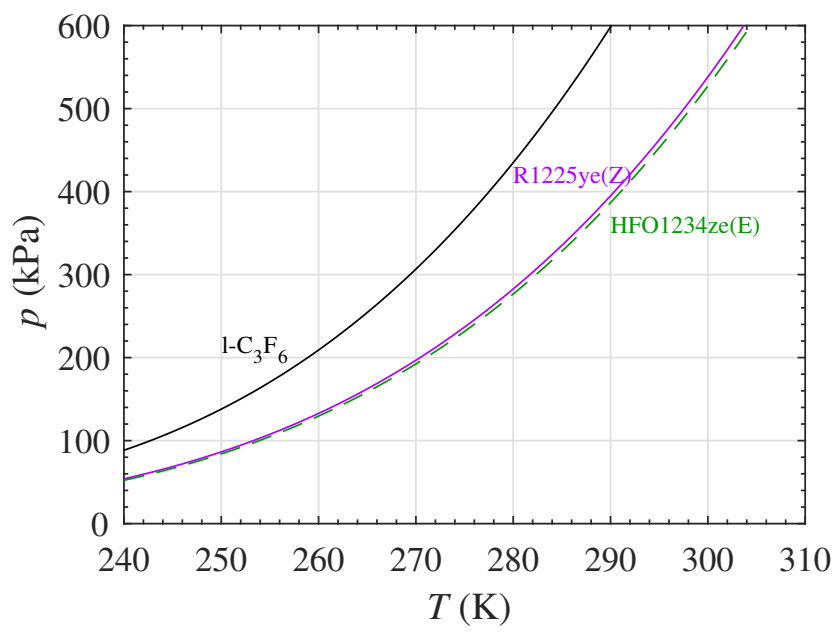

Figure 7. Vapor pressure curves of R1225ye(Z) [8], HFO1234ze(E) [20] and 1- $\mathrm{C}_{3} \mathrm{~F}_{6}$ [21].

ment $\left(k_{\mathrm{da}}\right.$, equation $\left.(2)\right)$, parent ion attachment, and autodetachment $\left(k_{\text {at }}, \tau^{-1}\right.$, equation $\left.(3)\right)$, collisional stabilization $\left(k_{\text {stab }}\right.$, equation (4)), and collisional detachment $\left(k_{\mathrm{det}}\right.$, equation (5)) [3].

$$
\begin{aligned}
& \mathrm{C}_{3} \mathrm{HF}_{5}+e \stackrel{k_{\mathrm{da}}}{\longrightarrow} \mathrm{A}^{-}+\mathrm{B}, \\
& \mathrm{C}_{3} \mathrm{HF}_{5}+e \stackrel{k_{\text {at }}}{\rightleftharpoons}\left(\mathrm{C}_{3} \mathrm{HF}_{5}\right)^{*}, \\
& \left(\mathrm{C}_{3} \mathrm{HF}_{5}\right)^{*}+\mathrm{C}_{3} \mathrm{HF}_{5} \stackrel{k_{\text {stab }}}{\longrightarrow} \mathrm{C}_{3} \mathrm{HF}_{5}^{-}+\mathrm{C}_{3} \mathrm{HF}_{5}, \\
& \left(\mathrm{C}_{3} \mathrm{HF}_{5}\right)^{*}+\mathrm{C}_{3} \mathrm{HF}_{5} \stackrel{k_{\text {det }}}{\longrightarrow} e+\mathrm{C}_{3} \mathrm{HF}_{5}+\mathrm{C}_{3} \mathrm{HF}_{5},
\end{aligned}
$$

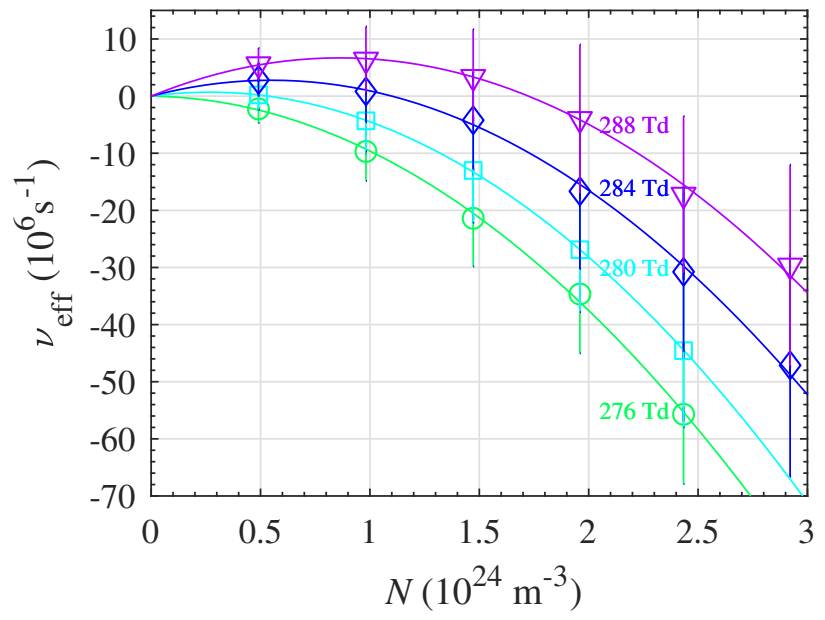

Figure 8. Regression of $\nu_{\text {eff }}$ for sample $E / N$ values with equation (7).

After several autodetachment lifetimes $\tau$, the effective ionization rate $\nu_{\text {eff }}$ can be expressed as

$\nu_{\text {eff }}(N)=\left(k_{\mathrm{i}}-k_{\text {da }}\right) N-\frac{k_{\text {quad }} N^{2}}{1+N / N_{\text {sat }}}$

with the two-body rate coefficient $\left(k_{\mathrm{i}}-k_{\mathrm{da}}\right)$ consisting of the difference of the total ionization rate coefficient and the dissociative attachment rate coefficient, the saturation density for three-body attachment $N_{\text {sat }}=\left(\left(k_{\text {stab }}+k_{\text {det }}\right) \cdot \tau\right)^{-1}$, and the three-body attachment rate coefficient $k_{\text {quad }}=k_{\text {at }} \cdot k_{\text {stab }} \cdot \tau$. Two limiting cases can be distinguished, which simplify the equation (6) either to

$\nu_{\text {eff }}(N)=\left(k_{\mathrm{i}}-k_{\text {da }}\right) N-k_{\text {quad }} N^{2}$,

or to

$\nu_{\text {eff }}(N)=\left(k_{\mathrm{i}}-k_{\mathrm{da}}\right) N-k_{\text {quad }} N_{\text {sat }} N$.

For $N \ll N_{\text {sat }}$ equation (7) is valid. $\nu_{\text {eff }}$ has a quadratic dependence on $N$. In this case, a pressure dependence of $(E / N)_{\text {crit }}$ is visible. For $N \gg N_{\text {sat }}$ the equation (8) is valid. $\nu_{\text {eff }}$ grows linearly with $N$. In this case, no pressure dependence of $(E / N)_{\text {crit }}$ is visible [3].

Figure 8 shows that $\nu_{\text {eff }}$ of R1225ye(Z) fits to equation (7). Consequently, the investigated pressure range of $\mathrm{R} 1225 \mathrm{ye}(\mathrm{Z})$ up to $14 \mathrm{kPa}$ corresponds to the case $N \ll N_{\text {sat }}$. For this case, it is not possible to determine $N_{\text {sat }}$, as it does not appear in equation (7). With the unknown value of $N_{\text {sat }}$, it is not possible to predict $(E / N)_{\text {crit }}$ for pressures higher than what were measured, since the three-body attachment could reach the saturation at a certain gas density. In this case, equation (8) becomes valid, and $\nu_{\text {eff }} / N$ becomes pressure-independent. 


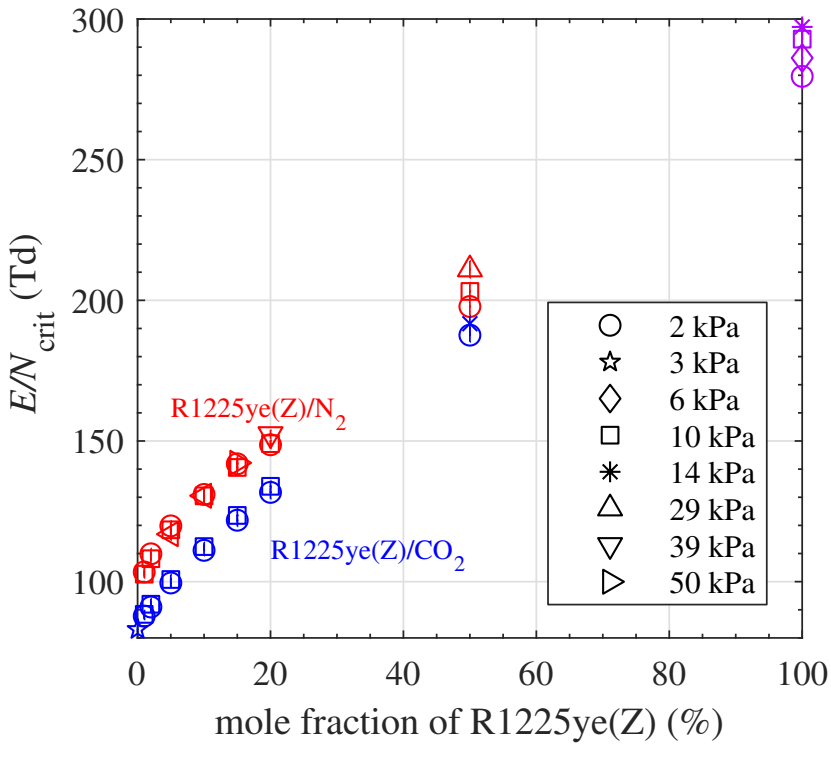

Figure 9. $(E / N)_{\text {crit }}$ of $\mathrm{R} 1225 \mathrm{ye}(\mathrm{Z})$ mixtures with $\mathrm{N}_{2}$ (red) and $\mathrm{CO}_{2}$ (blue).

\subsection{Mixtures with buffer gases $\mathrm{N}_{2}$ and $\mathrm{CO}_{2}$}

R1225ye(Z) shows almost no synergy with $\mathrm{N}_{2}$ and $\mathrm{CO}_{2}$. The density reduced critical electric fields $(E / N)_{\text {crit }}$ of R1225ye(Z) mixtures with $\mathrm{N}_{2}$ and $\mathrm{CO}_{2}$ at different pressures are summarized in figure 9 . The results can be split into two regions. In the region up to $15 \%$, the curves exhibit a bowing effect, and no pressure dependence is visible in the investigated range up to $50 \mathrm{kPa}$ with $\mathrm{N}_{2}$, and up to $10 \mathrm{kPa}$ with $\mathrm{CO}_{2}$. In the region above $15 \%,(E / N)_{\text {crit }}$ increases linearly with an increasing R1225ye(Z) fraction, and a pressure dependence is visible.

\section{Conclusion}

$(E / N)_{\text {crit }}$ of R1225ye(Z) is pressure dependent, as was previously observed for gases with similar structures: HFO1225ze(E) and $1-\mathrm{C}_{3} \mathrm{~F}_{6}$. According to the combination of the $(E / N)_{\text {crit }}$ and the boiling point, the insulating performance of pure $R 1225 y e(Z)$ is superior to $\mathrm{HFO} 1225 \mathrm{ze}(\mathrm{E})$, up to a pressure of at least $45 \mathrm{kPa}$, but inferior to $1-\mathrm{C}_{3} \mathrm{~F}_{6}$ or $\mathrm{SF}_{6}$. In the investigated pressure range, $\mathrm{R} 1225 \mathrm{ye}(\mathrm{Z})$ shows almost no synergy with $\mathrm{N}_{2}$ and $\mathrm{CO}_{2}$. The prediction of $(E / N)_{\text {crit }}$ for operating pressures of pure R1225ye(Z) and its mixtures is not possible, due to the possible saturation of the three-body attachment and unknown synergy behavior with buffer gases for higher pressures. Future investigations should be made to investigate the electric strength at higher pressures.

R1225ye(Z) could be considered as an insulation gas for medium voltage applications, due to its higher electric strength than HFO1234ze(E), equally low $\mathrm{GWP}<1$, and the same boiling point.

\section{Acknowledgments}

This work is financially supported by GE Grid (Switzerland) GmbH, Pfiffner Technologie AG, ABB Switzerland Ltd and Siemens AG.

\section{References}

[1] M Rabie, DA Dahl, SMA Donald, M Reiher and CM Franck. "Predictors for gases of high electrical strength". In: IEEE Transactions on Dielectrics and Electrical Insulation 20.3 (June 2013), pp. 856-863. ISSN: 1070-9878. DOI: 10 . 1109/TDEI . 2013.6518955.

[2] M Rabie and CM Franck. "Computational screening of new high voltage insulation gases with low global warming potential". In: IEEE Transactions on Dielectrics and Electrical Insulation 22.1 (Feb. 2015), pp. 296-302. ISSN: 10709878. DOI: 10.1109/TDEI.2014.004474.

[3] A Chachereau, M Rabie, and CM Franck. "Electron swarm parameters of the hydrofluoroolefine HFO1234ze". In: Plasma Sources Science and Technology 25.4 (2016), p. 045005. URL: http: / / stacks . iop. org / 0963-0252/ $25 / i=4 / a=$ 045005.

[4] A Chachereau and CM Franck. "Characterization of HFO1234ze mixtures with $\mathrm{N} 2$ and CO2 for use as gaseous electrical insulation media". In: Proceedings of the 20th International Symposium on High Voltage Engineering (ISH 2017). Cigre. 2017.

[5] T Aschwanden. "Die Ermittlung physikalischer Entladungsparameter in Isoliergasen und Isoliergasgemischen mit einer verbesserten SwarmMethode". PhD thesis. ETH Zurich, 1985. URL: http : / / e-collection . library . ethz . ch / view/eth:36996.

[6] G Myhre, D Shindell, F-M Breon, W Collins, J Fuglestvedt, J Huang, D Koch, J-F Lamarque, D Lee, B Mendoza, T Nakajima, A Robock, G Stephens, T Takemura and H Zhang. "Anthropogenic and Natural Radiative Forcing". In: Climate Change 2013: The Physical Science Basis. Contribution of Working Group I to the Fifth Assessment Report of the Intergovernmental Panel on Climate Change. Ed. by TF Stocker et al. Cambridge, United Kingdom and New York, NY, USA: Cambridge University Press, 2013. Chap. 8, pp. 659-740. ISBN: 978-1-107-66182-0. DOI: 10 . 1017 / CB09781107415324 . 018. URL: www.climatechange2013.org. 
[7] AA Lindley and TJ Noakes. "Consideration of Hydrofluoroolefins (HFOs) as potential candidate medical propellants". In: Mexichem Fluor online publication, (www.mexichemfluor.com) (2010).

[8] L Fedele, G Di Nicola, JS Brown, L Colla and S Bobbo. "Saturated pressure measurements of cis-pentafluoroprop-1-ene (R1225ye (Z))". In: International Journal of Refrigeration 69 (2016), pp. 243-250. DOI: https://doi.org/10.1016/ j.ijrefrig. 2015.10.012. URL: http://www . sciencedirect . com/science/article/pii / S0140700715003072.

[9] Apollo Scientific Ltd. Safety data sheet (Z)1,2,3,3,3-PENTAFLUOROPROPENE. 2016.

[10] Synquest Laboratories. (Z)-1,2,3,3,3-Pentafluoropropene Safety Data Sheet 13003Z5. 2015.

[11] PJ Chantry and RE Wootton. "A critique of methods for calculating the dielectric strength of gas mixtures". In: Journal of Applied Physics 52.4 (1981), pp. 2731-2739. ISSN: 00218979. DOI: 10.1063/1.329081. URL: http://scitation. aip.org/content/aip/journal/jap/52/4/10. 1063/1.329081.

[12] SR Hunter and LG Christophorou. "Pressuredependent electron attachment and breakdown strengths of unary gases and synergism of binary gas mixtures: A relationship". In: Journal of Applied Physics 57.9 (1985), pp. 4377-4385. DOI: 10.1063/1.334598. URL: https://doi.org/10. 1063/1.334598.

[13] Apollo Scientific Ltd. Certificate of analysis for a typical batch. 2016.

[14] International Electrotechnical Commission. "IEC 62271-1: 2007. High-voltage switchgear and controlgear-Part 1: Common specifications". In: International Electrotechnical Commission (2007), p. 252.

[15] DA Dahl, TH Teich, and CM Franck. "Obtaining precise electron swarm parameters from a pulsed Townsend setup". In: Journal of Physics D: Applied Physics 45.48 (2012), p. 485201. URL: http : / / stacks . iop. org / $0022-3727 / 45 / i=$ $48 / \mathrm{a}=485201$.

[16] LXcat Plasma Data Exchange Project. URL: www. lxcat.net.

[17] LC Pitchford, LL Alves, K Bartschat, SF Biagi, M-C Bordage, I Bray, CE Brion, MJ Brunger, L Campbell, A Chachereau and others. "LXCat: an Open-Access, Web-Based Platform for Data Needed for Modeling Low Temperature Plasmas". In: Plasma Processes and Polymers 14.1-2 (2017), p. 1600098.
[18] P Haefliger and CM Franck. "Detailed precision and accuracy analysis of swarm parameters from a pulsed Townsend experiment". In: Review of Scientific Instruments 89.2 (2018), p. 023114.

[19] GL Kennedy. "Toxicology of Fluorine-Containing Monomers". In: Critical reviews in toxicology 21.2 (1990), pp. 149-170. DOI: 10 . $3109 /$ 10408449009089877. URL: https://doi .org/ $10.3109 / 10408449009089877$.

[20] G Di Nicola, JS Brown, L Fedele, S Bobbo and C Zilio. "Saturated pressure measurements of trans-1, 3, 3, 3-tetrafluoroprop-1-ene (R1234ze (E)) for reduced temperatures ranging from 0.58 to 0.92". In: Journal of Chemical \&5 Engineering Data 57.8 (2012), pp. 2197-2202.

[21] GH Whipple. "Vapor-liquid equilibria of some fluorinated hydrocarbon systems". In: Industrial E3 Engineering Chemistry 44.7 (1952), pp. 16641667.

[22] LG Christophorou and SR Hunter. Electrons in dense gases Swarms of Ions and Electrons in Gases ed W Lindinger et al. 1984.

[23] NL Aleksandrov. "Three-body electron attachment to a molecule". In: Soviet Physics Uspekhi 31.2 (1988), p. 101. URL: http://stacks .iop. org $/ 0038-5670 / 31 / i=2 / a=R 01$. 